Gutiérrez, David. Deslocalizaciones internacionales: impacto sobre la estructura manufacturera española (1995-2005).

\title{
DESLOCALIZACIONES INTERNACIONALES: IMPACTO SOBRE LA ESTRUCTURA MANUFACTURERA ESPAÑOLA $(1995-2005)^{1}$
}

\author{
INTERNATIONAL OFFSHORING: IMPACT ON SPANISH \\ MANUFACTURING STRUCTURE (1995-2005)
}

\author{
DAVID GUTIÉRREZ SOBRAO \\ Investigador asociado \\ Universidad de Cantabria \\ gutierrezd@unican.es \\ Fecha recepción: 8 de diciembre de 2010 \\ Fecha aceptación: 30 de abril de 2011 \\ doi: 10.5209/rev_PADE.2011.v22.9
}

\section{RESUMEN}

El estudio que presentamos a continuación se centra en el impacto de los procesos de deslocalización internacional sobre la economía española. Delimitamos el campo de estudio al ámbito de las actividades industriales por ser éstas donde con mayor intensidad se han desarrollado este tipo de procesos y por su papel clave en el conjunto de la estructura económica. El lapso temporal escogido es el periodo 19952005, por cuestiones asociadas con la disponibilidad de datos. Aplicamos un enfoque de corte estructural y nos preguntamos por los cambios cualitativos inducidos por las deslocalizaciones internacionales en las manufacturas españolas. Nuestra hipótesis de trabajo es que las deslocalizaciones internacionales han afectado con mayor intensidad a los sectores de alto contenido tecnológico, contribuyendo a un mantenimiento del patrón de especialización industrial español.

PALABRAS CLAVE: deslocalización, estructura manufacturera, España.

JEL: F21, L6

\section{ABSTRACT}

The study that follows focuses on the impact of international offshoring process on the Spanish economy. We delimit the field of study to the manufacturing activity because it is here where these processes have been more intense, and also for its key role in the whole economic structure. The chosen time period is 1995-2005, for reasons associated with the availability of data. We apply a structural approach and wonder about qualitative changes in Spanish manufacturing induced by international offshoring. Our working hypothesis is that international offshoring has hit hardest in

\footnotetext{
${ }^{1}$ El autor agradece los comentarios y aportaciones de Fernando Luengo Escalonilla. El autor es responsable de los juicios incluidos, así como de los posibles errores u omisiones.
} 
Gutiérrez, David. Deslocalizaciones internacionales: impacto sobre la estructura manufacturera española (1995-2005).

areas of high technology, contributing to a maintenance of Spanish industrial specialization pattern.

KEY WORDS: Offshoring, manufacturing structure, Spain.

\section{INTRODUCCIÓN}

Las deslocalizaciones internacionales han capturado de forma intensa la atención pública durante los últimos años. Se han erigido en uno de los procesos más visibles dentro de aquellos que habitualmente se asocian con los discursos en materia de globalización. Sin embargo, la confusión acerca de la delimitación y alcance del fenómeno es generalizada. En el ámbito académico es objeto de atención creciente y son varios los estudios que han tratado de desentrañar su impacto en diversos ámbitos.

El estudio que presentamos a continuación se centra en el impacto de los procesos de deslocalización internacional sobre la economía española. Delimitamos el campo de análisis al ámbito de las actividades industriales por ser éstas donde con mayor intensidad se han desarrollado este tipo de procesos y por su papel clave en el conjunto de la estructura económica. El lapso temporal escogido es el periodo 19952005, por cuestiones asociadas con la disponibilidad de datos. Aplicamos un enfoque de corte estructural y nos preguntamos por los cambios cualitativos inducidos por las deslocalizaciones internacionales en las manufacturas españolas. Nuestra hipótesis de trabajo es que las deslocalizaciones internacionales han afectado con mayor intensidad a los sectores de alto contenido tecnológico, contribuyendo a un mantenimiento del patrón de especialización industrial español.

En la primera sección se presenta el marco teórico en el que se inserta el trabajo y aportamos algunas definiciones clave. En la segunda sección explicamos algunos aspectos metodológicos en materia de aplicación de taxonomías y se justifica su elección. En el tercer apartado se desarrolla el estudio aplicado, centrado en tres cuestiones: los cambios operados en la estructura del sector manufacturero español, la intensidad sectorial alcanzada por los procesos de deslocalización internacional y la evolución de la actividad de las multinacionales de capital extranjero. En la cuarta sección se aborda una discusión acerca de las implicaciones de los resultados obtenidos para los estudios sobre deslocalizaciones internacionales. Finalmente, se presentan las conclusiones del trabajo.

\section{MARCO TEÓRICO}

La existencia de grupos empresariales que operan en una escala supranacional dista de ser un fenómeno novedoso. No escasean los trabajos dedicados a estudiar los procesos de internacionalización de la producción en términos históricos y, sin entrar en precisiones de carácter cronológico, ésta no constituye en sí misma una característica propia de la trayectoria capitalista reciente. En las últimas décadas, sin embargo, parece haber adoptado perfiles distintos a los característicos en periodos precedentes.

La creciente profundización en la globalización productiva es un fenómeno que se manifiesta cuantitativamente en la trayectoria de la inversión directa extranjera (IDE), 
Gutiérrez, David. Deslocalizaciones internacionales: impacto sobre la estructura manufacturera española (1995-2005).

pero también en la magnitud de los flujos comerciales. El incremento en los intercambios transfronterizos presenta, además, un patrón cualitativamente diferente al de fases previas de expansión del comercio internacional. Si éstas se habían basado fundamentalmente en incrementos del comercio de tipo interindustrial, el periodo actual se caracteriza por un intenso crecimiento de los intercambios intraindustriales e intrafirma (Nayyar, 2006).

La evolución de la IDE y del comercio de productos intermedios constituyen síntomas de cambios de mayor alcance en la organización del proceso productivo por parte de las empresas multinacionales. El proceso de creciente ocupación de ámbitos geográficos distintos al nacional para la realización de partes del proceso productivo ha recibido diferentes denominaciones dentro de la literatura sobre la materia: desintegración internacional de la producción, descomposición de la cadena de valor, partición mundial de la producción, integración internacional de la producción, especialización vertical, fragmentación, especialización en subproductos, desarrollo de las redes mundiales de producción o cadenas globales de valor son algunas de ellas (Milberg, 2004). Sin embargo, todas ellas hacen referencia a la ampliada ocupación de espacios para el desarrollo del proceso productivo. A lo largo de este trabajo nos referiremos al mismo como fragmentación internacional de la producción.

Sin ánimo de ser exhaustivos, existen una serie de fenómenos que contribuyen a explicar la profundización en esta trayectoria de reubicación de la actividad productiva por parte de los grupos multinacionales. Por un lado, el desarrollo de las tecnologías de la información y la comunicación (TIC) ha permitido la aparición de configuraciones organizativas más dispersas desde el punto de vista geográfico (Martínez González-Tablas, 2007). La progresiva eliminación de barreras comerciales tanto en el marco de las negociaciones de la OMC como en acuerdos regionales, así como la generación de marcos regulatorios más favorables a la IDE han facilitado el proceso de internacionalización de la producción (Lall, 2003). El colapso de la Unión Soviética y la progresiva apertura de China han supuesto una ampliación de los espacios potencialmente ocupados por las empresas multinacionales, redundado en una ampliación de los mercados de trabajo a su disposición (Freeman, 2007).

En un contexto en el que los grupos multinacionales cuentan con una capacidad ampliada de acceder a nuevos ámbitos geográficos de un modo rentable, la inserción de las economías nacionales es susceptible de verse modificada. Los procesos de restructuración empresarial inducen transformaciones, de mayor o menor alcance, en las estructuras productivas domésticas de las que se derivan otras en la división internacional del trabajo. En este sentido, Milberg (2004) señala que en un contexto en el que el capital productivo actúa con un nivel acrecentado de movilidad la idea de una especialización comercial basada en ventajas comparativas derivada de las dotaciones factoriales pierde vigencia en detrimento de la noción de ventaja absoluta. Las empresas multinacionales tienen la capacidad de ubicarse en aquellos espacios que ofrecen un marco idóneo desde un puto de vista de la rentabilidad. Sin aplicar el reduccionismo de considerar que la elección se basa únicamente en un cálculo de costes, estas pueden escoger, por ejemplo, aquellas ubicaciones que ofrecen una mejor combinación de productividad y costes laborales. 
Gutiérrez, David. Deslocalizaciones internacionales: impacto sobre la estructura manufacturera española (1995-2005).

En este contexto de restructuración e incrementada movilidad surge la cuestión de las deslocalizaciones internacionales (DI, en adelante), fuertemente emparentadas con los procesos de fragmentación de la producción. Definimos como DI aquella parte de los procesos de reubicación de la producción que implican el traslado transfronterizo de actividad. Seguimos, por tanto, el enfoque dado por Luengo (2009) al adoptar una definición amplia y compartimos su advertencia de que resulta imposible abordar su estudio dejando al margen los procesos de carácter más amplio en que se inscriben.

Debe advertirse que bajo esta conceptualización amplia se insertan una multiplicidad de procesos de carácter diverso. Las DI se generan siempre en el marco de una restructuración empresarial, pero su naturaleza dista de ser idéntica. De este modo, podemos distinguir entre deslocalizaciones totales (aquellas que implican el cese total de la producción en un determinado país) y parciales (referidas únicamente a una fracción de los procesos). Especialmente relevante para el análisis del caso español es la distinción entre las deslocalizaciones acometidas por capital extranjero y aquellas otras desarrolladas por capitales nacionales, dado que las consecuencias potenciales derivadas del proceso pueden diverger. Una última distinción de interés es aquella que atiende a si el proceso de fragmentación implica o no externalización de la producción, es decir, si se mantiene el control de la propiedad o se recurre a proveedores para su materialización. Estas matizaciones no captan toda la diversidad de variantes implícitas en las deslocalizaciones pero resultan útiles para el estudio que se propone.

\section{ENFOQUE ESTRUCTURAL Y UTILIZACIÓN DE TAXONOMÍAS}

La teoría económica convencional ha tendido a ignorar las consideraciones relativas a la importancia de la estructura productiva. Desde un enfoque que parte de la noción de que la especialización de cada economía debe surgir de sus características fundamentales, es decir, de su dotación relativa de trabajo (capital humano), capital físico y recursos naturales (Hausmann et al., 2007), se ha pasado por alto la relevancia que la materialización concreta del tejido productivo (qué se produce, qué se comercia) tiene para el desarrollo económico. De este modo, en un contexto en el que los mercados funcionen sin trabas (regulaciones) y exista apertura al exterior, la especialización según el criterio de la ventaja comparativa emanada de esa dotación relativa de factores productivos generará la estructura productiva óptima, tanto desde el punto de vista estático como desde una óptica dinámica (Lall, 2003).

El presente trabajo se realiza desde un enfoque que considera que el tipo de materialización concreta que adopta la estructura productiva constituye un elemento relevante desde el punto de vista del desarrollo de un país. Partimos de la noción de que existen importantes diferencias cualitativas y cuantitativas en el impacto que las distintas actividades productivas tienen sobre la trayectoria económica de un determinado área geográfica. Se trata de un resultado avalado por la evidencia empírica. Hausmann et al. (2007) muestran la vinculación existente entre la composición de la canasta exportadora y el nivel de desarrollo: los países que comercian con bienes de más alto valor añadido acceden a mayores niveles de ingreso. Hausmann y Klinger (2006), partiendo de la idea de que existe una amplia diversidad de complementariedades entre actividades productivas, concluyen que la 
Gutiérrez, David. Deslocalizaciones internacionales: impacto sobre la estructura manufacturera española (1995-2005).

posibilidad de acceder a procesos de upgrading y cambio estructural no es equivalente en todos los patrones de especialización. Los países orientados más intensamente hacia la producción de manufacturas tienen mayores posibilidades de "saltar" hacia nuevos sectores, debido a la existencia de sinergias en el ámbito productivo. Rodrik (2006) resume parte de los resultados obtenidos a partir de este tipo de trabajos de carácter aplicado y concluye que los sectores industriales y, especialmente los no tradicionales, juegan un papel clave en los procesos de crecimiento y desarrollo.

Desde la perspectiva mencionada, se propone un estudio del impacto de las DI sobre la estructura manufacturera española teniendo en cuenta estas connotaciones de corte cualitativo. Para ello se aplican una serie de taxonomías de tipo sectorial con el objetivo de diferenciar entre actividades según los siguientes criterios: (i) intensidad tecnológica, (ii) vinculación con las TIC y (iii) nivel de cualificación implícito.

No se desconocen, en este sentido, las problemáticas asociadas con la utilización de estadísticas de naturaleza sectorial, en un contexto como el descrito, en el que la fragmentación del proceso productivo tiende a diluir las fronteras de lo que tradicionalmente se ha definido como sector. ${ }^{2}$ Sin embargo, existen limitaciones metodológicas que imponen la adopción de esta óptica. Los datos necesarios para la obtención de los indicadores de deslocalización internacional empleados a continuación únicamente se presentan con desagregación (limitada) sectorial.

De igual modo, no se ignora la relativa arbitrariedad implícita en la utilización de taxonomías. El establecimiento de umbrales siempre implica una cierta subjetividad y los indicadores utilizados para su construcción suelen capturar únicamente una parte de los procesos en juego. Sin embargo, se considera que el potencial analítico de los datos presentados se ve notablemente incrementado a través de la ordenación cualitativa de las actividades manufactureras.

La primera de las taxonomías implementada emplea criterios de agrupación basados en la intensidad tecnológica de cada una de las actividades manufactureras y es proporcionada por la OCDE (2005). Para su elaboración se emplean indicadores del esfuerzo en I+D, tomando en consideración indicadores indirectos ( + +D implícita en los productos intermedios consumidos por un sector) y directos (gasto en I+D del sector). La clasificación resultante distingue entre actividades de tecnología alta, media-alta, media-baja y baja (véase Cuadro 1).

Las otras dos clasificaciones incorporadas se han tomado de Robinson et al. (2003). La primera de ellas atiende a la vinculación de los diversos sectores respecto a las TIC, distinguiendo entre sectores productores, usuarios y no usuarios (véase Cuadro 2). Para su elaboración se parte de la identificación de una serie de sectores manufactureros productores de TIC de acuerdo con la definición dada por la OCDE. La detección de aquellas actividades que realizan un uso intensivo de TIC para su proceso productivo se basa en datos de participación del capital TIC en el total de cada sector para EE.UU.

\footnotetext{
${ }^{2}$ Véase, por ejemplo, Huberty (2010). 
Gutiérrez, David. Deslocalizaciones internacionales: impacto sobre la estructura manufacturera española (1995-2005).

Cuadro 1. Actividades manufactureras según intensidad tecnológica

\section{Código Nace 3}

Rama

\begin{tabular}{|c|c|}
\hline \multicolumn{2}{|r|}{ ALTA } \\
\hline 244 & Fabricación de productos farmacéuticos \\
\hline 30 & Fabricación de máquinas de oficina y equipos informáticos \\
\hline 32 & $\begin{array}{l}\text { Fabricación de material electrónico; fabricación de equipo y aparatos de radio, } \\
\text { televisión y comunicaciones }\end{array}$ \\
\hline 33 & $\begin{array}{l}\text { Fabricación de equipo e instrumentos médico-quirúrgicos, de precisión, óptica y } \\
\text { relojería }\end{array}$ \\
\hline 353 & Construcción aeronáutica y espacial \\
\hline \multicolumn{2}{|r|}{ MEDIA-ALTA } \\
\hline 24-244 & Industria química (excepto productos farmacéuticos) \\
\hline 29 & Fabricación de máquinas, equipo y material mecánico \\
\hline 31 & Fabricación de maquinaria y material eléctrico \\
\hline 34 & Fabricación de vehículos de motor, remolques y semirremolques \\
\hline 352 & Fabricación de material ferroviario \\
\hline 354 & Fabricación de motocicletas y bicicletas \\
\hline 355 & Fabricación de otro material de transporte \\
\hline \multicolumn{2}{|r|}{ MEDIA-BAJA } \\
\hline 23 & Coquerías, refino de petróleo y tratamiento de combustibles nucleares \\
\hline 25 & Fabricación de productos de caucho y materias plásticas \\
\hline 26 & Fabricación de otros productos minerales no metálicos \\
\hline 27 & Metalurgia \\
\hline 28 & Fabricación de productos metálicos, excepto maquinaria y equipo \\
\hline 351 & Construcción y reparación naval \\
\hline \multicolumn{2}{|r|}{ BAJA } \\
\hline 15 & Industrias de productos alimenticios y bebidas \\
\hline 16 & Industria del tabaco \\
\hline 17 & Industria textil \\
\hline 18 & Industria de la confección y de la peletería \\
\hline 19 & $\begin{array}{l}\text { Preparación, curtido y acabado del cuero; fabricación de artículos de } \\
\text { marroquinería y viaje: artículos de guarnicionería, talabartería y zapatería }\end{array}$ \\
\hline 20 & Industria de la madera y del corcho, excepto muebles; cestería y espartería \\
\hline 21 & Industria del papel \\
\hline 22 & Edición, artes gráficas y reproducción de soportes grabados \\
\hline 36 & Fabricación de muebles; otras industrias manufactureras \\
\hline 37 & Reciclaje \\
\hline
\end{tabular}


Gutiérrez, David. Deslocalizaciones internacionales: impacto sobre la estructura manufacturera española (1995-2005).

Cuadro 2. Actividades manufactureras según vinculación con las TIC

Código Nace 1
Rama

\section{TIC - Productores}

30

Fabricación de máquinas de oficina y equipos informáticos

313

Fabricación de hilos y cables eléctricos aislados

32

Fabricación de material electrónico; fabricación de equipo y aparatos de radio, televisión y comunicaciones

331

332

333

Fabricación de equipo e instrumentos médico-quirúrgicos y de aparatos ortopédicos

Fabricación de instrumentos y aparatos de medida, verificación, control, navegación y otros fines, excepto equipos de control de procesos industriales Fabricación de equipo de control de procesos industriales

\section{TIC - Usuarios}

Industria de la confección y de la peletería

Edición, artes gráficas y reproducción de soportes grabados

29 Fabricación de máquinas, equipo y material mecánico

$31-313$

Fabricación de maquinaria y material eléctrico

33X Otros instrumentos

$35 \quad$ Otros equipos de transporte

36 Fabricación de muebles; otras industrias manufactureras

$37 \quad$ Reciclaje

\section{TIC - No usuarios}

\begin{tabular}{ll}
15 & Industrias de productos alimenticios y bebidas \\
16 & Industria del tabaco \\
17 & Industria textil \\
19 & Preparación, curtido y acabado del cuero; fabricación de artí́culos de \\
20 & marroquinería y viaje: artículos de guarnicionería, talabartería y zapatería \\
21 & Industria de la madera y del corcho, excepto muebles; cestería y espartería \\
23 & Industria del papel \\
24 & Coquerías, refino de petróleo y tratamiento de combustibles nucleares \\
25 & Industria química \\
26 & Fabricación de productos de caucho y materias plásticas \\
27 & Metalurgia \\
28 & Fabricación de productos metálicos, excepto maquinaria y equipo \\
34 & Fabricación de vehículos de motor, remolques y semirremolques \\
\hline
\end{tabular}

Fuente: Robinson et al. (2003). 
Gutiérrez, David. Deslocalizaciones internacionales: impacto sobre la estructura manufacturera española (1995-2005).

Cuadro 3. Actividades manufactureras según niveles relativos de cualificación del trabajo requeridos

Código Nace $1 \quad$ Rama

\begin{tabular}{|c|c|}
\hline \multicolumn{2}{|r|}{ Alta cualificación } \\
\hline 23 & Coquerías, refino de petróleo y tratamiento de combustibles nucleares \\
\hline 24 & Industria química \\
\hline 30 & Fabricación de máquinas de oficina y equipos informáticos \\
\hline 32 & $\begin{array}{l}\text { Fabricación de material electrónico; fabricación de equipo y aparatos de radio, } \\
\text { televisión y comunicaciones }\end{array}$ \\
\hline \multicolumn{2}{|r|}{ Media-alta cualificación } \\
\hline 33 & $\begin{array}{l}\text { Fabricación de equipo e instrumentos médico-quirúrgicos, de precisión, óptica y } \\
\text { relojería }\end{array}$ \\
\hline 35 & Otros equipos de transporte \\
\hline \multicolumn{2}{|r|}{ Media-baja cualificación } \\
\hline 20 & Industria de la madera y del corcho, excepto muebles; cestería y espartería \\
\hline 21 & Industria del papel \\
\hline 22 & Edición, artes gráficas y reproducción de soportes grabados \\
\hline 28 & Fabricación de productos metálicos, excepto maquinaria y equipo \\
\hline 29 & Fabricación de máquinas, equipo y material mecánico \\
\hline 31 & Fabricación de maquinaria y material eléctrico \\
\hline \multicolumn{2}{|r|}{ Baja cualificación } \\
\hline 15 & Industrias de productos alimenticios y bebidas \\
\hline 16 & Industria del tabaco \\
\hline 17 & Industria textil \\
\hline 18 & Industria de la confección y de la peletería \\
\hline 19 & $\begin{array}{l}\text { Preparación, curtido y acabado del cuero; fabricación de artículos de } \\
\text { marroquinería y viaje: artículos de guarnicionería, talabartería y zapatería }\end{array}$ \\
\hline 25 & Fabricación de productos de caucho y materias plásticas \\
\hline 26 & Fabricación de otros productos minerales no metálicos \\
\hline 27 & Metalurgia \\
\hline 34 & Fabricación de vehículos de motor, remolques y semirremolques \\
\hline 36 & Fabricación de muebles; otras industrias manufactureras \\
\hline 37 & Reciclaje \\
\hline
\end{tabular}

Finalmente, se emplea una taxonomía que agrupa a los sectores según el tipo de trabajo del que hacen un uso intensivo, distinguiendo entre trabajo altamente cualificado, con cualificación intermedia-alta o intermedia-baja, y con baja cualificación. Para su elaboración Robinson et al. (2003) emplean estadísticas 
Gutiérrez, David. Deslocalizaciones internacionales: impacto sobre la estructura manufacturera española (1995-2005).

ocupacionales sobre niveles formativos en EE.UU, Reino Unido y UE15. La clasificación resultante se incorpora en el Cuadro 3.

\section{IMPACTO DE LAS DESLOCALIZACIONES INTERNACIONALES SOBRE LA ESTRUCTURA INDUSTRIAL ESPAÑOLA (1995-2005)}

Las DI, tal y como han sido definidas en el presente trabajo, se introducen en los márgenes de una amplia variedad de procesos, con los que deben ser vinculadas, pero no estableciéndose una relación de identidad. De este modo, afectan a la magnitud y dirección del comercio internacional, la inversión extranjera directa, los movimientos transfronterizos de personas o las transferencias internacionales de tecnología (Luengo y Álvarez, 2009). Este carácter poliédrico, sumado a la inexistencia de estadísticas que aborden de forma específica e integral su medición, explica que para su estudio se hayan utilizado una amplia variedad de técnicas ${ }^{3}$, casi todas ellas haciendo uso de indicadores proxy.

En el presente trabajo tratamos de caracterizar el impacto de las DI sobre la estructura sectorial de la industria española mediante una aproximación a través de tres vertientes. En primer lugar, presentamos un análisis de la evolución de la estructura productiva para el periodo considerado. Tratamos de identificar los sectores que muestran menor dinamismo en términos de producción y empleo y que pierden relevancia en el conjunto de la estructura manufacturera. Los procesos de deslocalización no tienen porque estar asociados con un deterioro de las principales variables macro, pero la atonía en ciertas ramas es indicio de procesos de restructuración en curso.

A continuación acudimos a la explotación de las tablas input-output proporcionadas por la STAN Database de la OCDE que suministran información acerca de las adquisiciones intermedias por sector según si su origen es doméstico o importado, tratando de aproximar la intensidad con la que se están implementando procesos deslocalizadores. Se trata de uno de los indicadores más utilizados en la literatura en la materia y el que mejor permite caracterizar la dinámica del fenómeno en ausencia de estimaciones directas.

Finalizamos con un análisis centrado en la evolución de la contribución de las empresas multinacionales de capital extranjero a la actividad manufacturera española. El sector manufacturero español se caracteriza por una amplia penetración de los grupos foráneos, especialmente en las ramas de mayor contenido tecnológico, por lo que atender a su evolución dentro de la dinámica industrial constituye un elemento relevante a la hora de aproximar el impacto de las DI.

\subsection{Estructura Industrial Española (1995-2005)}

Presentamos un análisis de la evolución de la estructura manufacturera atendiendo a dos de sus variables básicas: valor añadido y empleo. Por motivos de espacio no es posible abordar de forma completa todas las connotaciones de las transformaciones acaecidas (por ejemplo, en el ámbito comercial). Sin embargo, nos referimos a algunos trabajos en la materia para completar la panorámica. El objetivo

\footnotetext{
${ }^{33}$ Un repaso de las técnicas aplicadas se puede encontrar en Luengo (2009) y en Bottini et al. (2007).
} 
Gutiérrez, David. Deslocalizaciones internacionales: impacto sobre la estructura manufacturera española (1995-2005).

es detectar las principales dinámicas a nivel sectorial, utilizando para ello las taxonomías propuestas.

Los datos sobre evolución sectorial de las manufacturas españolas han sido tomados de las estadísticas proporcionadas por el proyecto EU Klems (2008) para un nivel de desagregación de 72 ramas. Para España esta base de datos utiliza como fuente principal la Contabilidad Nacional proporcionada por el Instituto Nacional de Estadística (INE), complementando ésta con un conjunto de encuestas de carácter sectorial. La principal ventaja que se deriva de la utilización de EU Klems es la posibilidad de obtener datos según niveles de desagregación de tres dígitos NACE para algunas ramas especialmente relevantes.

El sector manufacturero español se ha caracterizado tradicionalmente por una especialización relativa en las actividades con menores exigencias tecnológicas. Sin embargo, en términos de trayectoria histórica este rasgo se ha visto progresivamente relajado en un proceso que ha supuesto un cierto declive relativo de las actividades tradicionales y un auge de aquellas con requerimientos tecnológicos altos e intermedios, aunque sin que esto haya supuesto una superación del patrón de especialización basado en los sectores más tradicionales (Velasco y Plaza, 2003).

Esta trayectoria de creciente, aunque limitada, relevancia de las actividades de mayor intensidad tecnológica se ha visto, sin embargo, truncada en el periodo 19952005, como es posible advertir en el Cuadro 4. Durante este lapso de tiempo las actividades de mayor contenido tecnológico sufrieron una reducción en su participación relativa en el valor añadido bruto (VAB) manufacturero, en lo que supone una tendencia rupturista respecto a su creciente importancia en décadas previas. En términos de contribución al empleo industrial también experimentan un marcado estancamiento, presentando la menor tasa de variación media para el conjunto del periodo. Este cambio de tendencia resulta aún más significativo si se toma en consideración la escasa dimensión relativa de partida de estas actividades en comparación con los países de su entorno (Molero, 2009).

Dentro de las restantes ramas industriales crecen con mayor intensidad las agrupadas bajo niveles intermedios de intensidad tecnológica, especialmente las de intensidad media-baja. El dinamismo en estos sectores se produce tanto en términos de avance del valor añadido generado como de empleo, y se sustancia en un incremento de su importancia relativa dentro de la estructura manufacturera española. El corolario del intenso crecimiento de las actividades intermedias es la pérdida de cuota en los sectores calificados como de baja tecnología, que registran menores avances en términos de producción y empleo.

La trayectoria seguida por las actividades manufactureras de alta tecnología tiene su origen en el fuerte retroceso de los sectores productores de TIC (véase Cuadro 5). Partiendo de un peso relativo sobre el total industrial inferior al de los países de su entorno (Robinson et al., 2003), se produce una significativa pérdida de cuota en el lapso 1995-2005 como consecuencia de una importante caída en términos de generación de valor añadido. Son las actividades manufactureras que hacen uso intensivo de las TIC las que muestran un mejor comportamiento para el periodo estudiado, registrando un importante crecimiento que se refleja en su creciente importancia dentro de las actividades industriales. 
Cuadro 4. Estructura manufacturera española, VAB y empleo, 1995-2005

\begin{tabular}{|c|c|c|c|c|c|c|c|}
\hline & \multicolumn{5}{|c|}{ VAB } & \multicolumn{2}{|c|}{ Empleo } \\
\hline & & \multicolumn{3}{|c|}{ Participación relativa } & \multirow{2}{*}{$\frac{\text { TV }}{95-05}$} & \multirow{2}{*}{$\begin{array}{c}\text { Total } \\
\text { Diferencia }\end{array}$} & \multirow{2}{*}{$\begin{array}{c}\text { TV } \\
95-05\end{array}$} \\
\hline & & 1995 & 2005 & Diferencia & & & \\
\hline NACE & Alta tecnología & $7,73 \%$ & $6,26 \%$ & $-1,47 \%$ & $0,02 \%$ & 9,424 & $0,67 \%$ \\
\hline 244 & Fabricación de productos farmacéuticos & $2,93 \%$ & $2,71 \%$ & $-0,22 \%$ & $1,34 \%$ & 6,993 & $1,56 \%$ \\
\hline 30 & Fabricación de maquinaria de oficina, contabilidad e informática & $1,21 \%$ & $0,66 \%$ & $-0,56 \%$ & $-3,94 \%$ & $-9,758$ & $-5,62 \%$ \\
\hline 32 & Fabricación de equipo y aparatos de radio, televisión y comunicaciones & $2,00 \%$ & $1,11 \%$ & $-0,89 \%$ & $-3,70 \%$ & $-5,760$ & $-1,52 \%$ \\
\hline 33 & Fabricación de instrumentos médicos, ópticos y de precisión y fabricación de relojes & $1,02 \%$ & $1,01 \%$ & $-0,01 \%$ & $2,08 \%$ & 10,510 & $4,23 \%$ \\
\hline \multirow[t]{2}{*}{353} & Fabricación de aeronaves y naves espaciales & $0,56 \%$ & $0,77 \%$ & $0,21 \%$ & $5,42 \%$ & 7,439 & $5,10 \%$ \\
\hline & Media-alta & $24,72 \%$ & $26,50 \%$ & $1,78 \%$ & $2,86 \%$ & 162,858 & $2,88 \%$ \\
\hline $24 x$ & Productos químicos, excluyendo framacéuticos & $6,51 \%$ & $6,32 \%$ & $-0,18 \%$ & $1,86 \%$ & 20,095 & $2,00 \%$ \\
\hline 29 & Fabricación de maquinaria y equipo n.c.p. & $6,11 \%$ & $7,61 \%$ & $1,50 \%$ & $4,41 \%$ & 92,501 & $5,11 \%$ \\
\hline 31 & Fabricación de maquinaria y aparatos eléctricos n.c.p. & $3,11 \%$ & $3,48 \%$ & $0,38 \%$ & $3,32 \%$ & 16,909 & $2,14 \%$ \\
\hline 34 & Fabricación de vehículos automotores, remolques y semirremolques & $8,43 \%$ & $8,48 \%$ & $0,05 \%$ & $2,21 \%$ & 29,633 & $1,55 \%$ \\
\hline \multirow[t]{2}{*}{$35 x$} & Otro equipo de transporte & $0,57 \%$ & $0,60 \%$ & $0,03 \%$ & $2,71 \%$ & 3,719 & $2,67 \%$ \\
\hline & Media-baja & $29,57 \%$ & $32,17 \%$ & $2,60 \%$ & $3,01 \%$ & 254,623 & $3,71 \%$ \\
\hline 23 & Fabricación de coque, productos de la refinación del petróleo y combustible nuclear & $2,15 \%$ & $1,58 \%$ & $-0,57 \%$ & $-0,95 \%$ & 0,577 & $0,69 \%$ \\
\hline 25 & Fabricación de productos de caucho y plástico & $4,01 \%$ & $4,71 \%$ & $0,70 \%$ & $3,80 \%$ & 33,917 & $3,37 \%$ \\
\hline 26 & Fabricación de otros productos minerales no metálicos & $7,32 \%$ & $8,47 \%$ & $1,15 \%$ & $3,64 \%$ & 46,157 & $2,79 \%$ \\
\hline $27-28$ & Metálicas básicas y productos metálicos & $15,13 \%$ & $16,41 \%$ & $1,28 \%$ & $2,98 \%$ & 174,683 & $4,60 \%$ \\
\hline \multirow[t]{2}{*}{351} & Construcción y reparación de buques y otras embarcaciones & $0,96 \%$ & $1,01 \%$ & $0,04 \%$ & $2,60 \%$ & $-0,711$ & $-0,23 \%$ \\
\hline & Baja & $37,97 \%$ & $35,07 \%$ & $-2,91 \%$ & $1,34 \%$ & 201,523 & $1,74 \%$ \\
\hline $15-16$ & Elaboración de productos alimenticios, bebidas y tabaco & $15,59 \%$ & $13,09 \%$ & $-2,50 \%$ & $0,38 \%$ & 60,808 & $1,51 \%$ \\
\hline $17-19$ & Fabricación de productos textiles, cuero y calzado & $7,79 \%$ & $5,46 \%$ & $-2,34 \%$ & $-1,43 \%$ & $-2,221$ & $-0,08 \%$ \\
\hline 20 & Producción de madera y fabricación de productos de madera y corcho & $2,37 \%$ & $2,35 \%$ & $-0,02 \%$ & $2,04 \%$ & 35,102 & $3,83 \%$ \\
\hline $21-22$ & Fabricación de papel y de productos de papel y actividades de edición e impresión & $7,92 \%$ & $9,26 \%$ & $1,35 \%$ & $3,76 \%$ & 58,610 & $3,13 \%$ \\
\hline $36 \mathrm{t} 37$ & Fabricación de muebles; industrias manufactureras n.c.p. y reciclado & $4,30 \%$ & $4,91 \%$ & $0,61 \%$ & $3,51 \%$ & 49,225 & $2,55 \%$ \\
\hline
\end{tabular}


Gutiérrez, David. Deslocalizaciones internacionales: impacto sobre la estructura manufacturera española (1995-2005).

Cuadro 5. Estructura del VAB en las manufacturas españolas, 1995-2005

\begin{tabular}{cccccc}
\hline & \multicolumn{2}{c}{ VAB } & \multicolumn{2}{c}{ Empleo } \\
\hline \multicolumn{2}{c}{ Participación relativa } & TV $^{*}$ & Total & TV \\
\hline 1995 & 2005 & Diferencia & $95-05$ & Diferencia & $95-05$
\end{tabular}

\begin{tabular}{lrrrrrr}
\hline \multicolumn{1}{c}{ TIC } & & & & & & \\
Productores TIC & $4,44 \%$ & $2,98 \%$ & $-1,46 \%$ & $1,85 \%$ & $-4,727$ & $-0,56 \%$ \\
Usuarios TIC & $23,52 \%$ & $26,69 \%$ & $3,17 \%$ & $3,45 \%$ & 212,159 & $2,75 \%$ \\
No usuarios TIC & $72,04 \%$ & $70,33 \%$ & $-1,71 \%$ & $1,90 \%$ & 420,995 & $2,48 \%$ \\
\multicolumn{1}{c}{ Cualificación } & & & & & & \\
Alta & $14,80 \%$ & $12,38 \%$ & $-2,42 \%$ & $0,34 \%$ & 12,146 & $0,58 \%$ \\
Media-alta & $3,12 \%$ & $3,40 \%$ & $0,28 \%$ & $3,03 \%$ & 20,958 & $2,47 \%$ \\
Media-baja & $27,91 \%$ & $32,78 \%$ & $4,88 \%$ & $3,81 \%$ & 357,436 & $4,39 \%$ \\
Baja & $54,17 \%$ & $51,44 \%$ & $-2,74 \%$ & $1,62 \%$ & 237,887 & $1,65 \%$ \\
\hline Tasa de variación anual media & & & & & \\
Fuente: elaboración propia a partir de EU Klems. & & & &
\end{tabular}

Los resultados obtenidos mediante la aplicación de la taxonomía ocupacional son coherentes con las trayectorias dibujadas previamente. Las manufacturas que hacen un uso más intensivo del trabajo altamente cualificado muestran un estancamiento para el conjunto del periodo que redunda en una pérdida de cuota en el conjunto del sector industrial. En cambio, crecen los ámbitos que requieren trabajo con niveles de formación media-baja.

Si atendemos a un análisis para un nivel de desagregación sectorial (véase Cuadro 4), las ramas que incrementan en mayor medida su cuota dentro de la producción manufacturera son aquellas con vínculos más fuertes respecto de los requerimientos de insumos procedentes de las actividades de construcción, ámbito clave en la expansión económica española durante el periodo. ${ }^{4}$ Es el caso de las ramas de "fabricación de otros productos no metálicos", "metálicas básicas y productos metálicos", "fabricación de productos de caucho y plástico"; y "fabricación de maquinaria y equipo"; todas ellas incluidas en las ramas de densidad tecnológica media. Dentro de los sectores incorporados en la categoría de alta tecnología, únicamente las ramas aeronáuticas, altamente dependientes de la iniciativa pública, alcanzaron una mejora en su posición relativa. Especialmente relevante fue la pérdida de cuota en las actividades asociadas a la "fabricación de maquinaria de oficina y de equipos de comunicaciones" y a "fabricación de equipo y aparatos de radio, televisión y comunicaciones".

Álvarez et al. (2007), utilizando índices de especialización exportadora y de ventaja comparativa revelada para el periodo 1995-2004, concluyen que las transformaciones en la estructura manufacturera española han corrido paralelas a

\footnotetext{
${ }^{4}$ De acuerdo con el Observatorio Industrial del Sector del Construcción (2009) las ramas industriales más dependientes en España de la demanda procedente de la construcción son las siguientes (más del $10 \%$ de la demanda procedente de este sector): fabricación de otros productos no metálicos; producción de madera y fabricación de productos de madera y corcho; metálicas básicas y productos metálicos; fabricación de muebles, industrias manufactureras n.c.p. y reciclado, fabricación de productos de caucho y plástico; y Fabricación de maquinaria y equipo n.c.p.
} 
Gutiérrez, David. Deslocalizaciones internacionales: impacto sobre la estructura manufacturera española (1995-2005).

las registradas en la vertiente comercial. En un contexto de fuerte deterioro del saldo comercial industrial, las exportaciones españolas en los sectores de elevada intensidad tecnológica registran un menor dinamismo que en los países de su entorno, incrementándose la especialización relativa en los sectores tradicionales e intermedios. Gordo (2007) muestra que la importante desventaja española en estos sectores, los de mayor crecimiento en términos de demanda mundial, contribuye a la aparición de déficits comercial recurrentes en las actividades manufactureras.

En síntesis, el análisis del comportamiento de la estructura productiva manufacturera española para el periodo 1995-2005 parece confirmar una tendencia hacia la consolidación de un patrón de especialización productiva centrado en actividades de intensidad tecnológica intermedia, aunque los sectores tradicionales mantienen gran parte de su relevancia. Especialmente significativa es la pérdida de cuota de los sectores de alta tecnología, productores de TIC y que hacen uso de un trabajo más altamente cualificado. La trayectoria previa parecía apuntar hacia una creciente importancia de estas ramas, convergiendo hacia los niveles presentados por otros países europeos. Esta tendencia se ha visto truncada en el periodo 1995-2005.

\subsection{Impacto sectorial de las deslocalizaciones internacionales: enfoque input- output}

\subsubsection{Cuestiones metodológicas}

El incremento en el volumen de comercio de productos intermedios constituye uno de los efectos inducidos más evidentes de la fragmentación internacional de la producción y las DI. La reubicación de fases del proceso productivo en emplazamientos dispersos se materializa en flujos incrementados de producción que se moviliza a través de las fronteras nacionales, exacerbando las estadísticas comerciales. Es por ello que una parte importante de la literatura centrada en el estudio de este fenómeno trata de capturar la intensidad del mismo mediante fuentes estadísticas sobre adquisición transfronteriza de insumos. Una de las alternativas más adecuadas para realizar este tipo de medición son las tablas inputoutput (Cadarso et al., 2007).

Las tablas input-output cuantifican los requerimientos de los distintos productos intermedios realizados por los diferentes sectores, según distintos niveles de desagregación y distinguiendo entre inputs domésticos e importados. Permiten aproximar tanto la intensidad adquirida por los procesos de fragmentación de la producción de forma genérica, mediante la evolución del total de insumos utilizados, como aquella parte que se sustancia en movimientos transfronterizos, atendiendo a la evolución de los inputs importados. Su construcción permite también diferenciar entre aquella fracción de los consumos que tiene un origen intraindustrial (procedentes de la misma rama de actividad) y aquella otra que implica intercambio intersectorial.

Los indicadores empleados en el presente trabajo siguen la propuesta original de Feenstra y Hanson (1999) en su trabajo sobre el impacto de las DI sobre la desigualdad salarial en EE.UU. entre trabajadores cualificados y no cualificados, con algunas matizaciones que se explican a continuación. Se distingue entre indicadores restringido, diferencia y amplio de DI. Para su construcción utilizamos las tablas 
Gutiérrez, David. Deslocalizaciones internacionales: impacto sobre la estructura manufacturera española (1995-2005).

input-output simétricas que proporciona la OCDE en su Stan Database para España. El marco input-output de la OCDE proporciona datos industria por industria con un nivel de desagregación de dos dígitos según ISIC Rev. $3^{5}$. Para la transformación de las tablas a términos constantes se han utilizado los deflactores para un nivel de desagregación de dos y tres dígitos NACE 1 proporcionados por EU Klems (2008). ${ }^{6}$

La expresión del indicador de Deslocalización Internacional Restringida (DIR) para el sector i es la siguiente:

$$
D I R_{i}=\frac{m_{i \bar{i}}}{Y_{i}}
$$

Donde $\mathrm{m}_{\mathrm{ii}}$ es la cantidad de insumos importados procedentes del sector i empleados por el sector i e $Y_{i}$ la producción total del sector i. La expresión del indicador de Deslocalización Internacional Diferencia (DID) para el sector i es la siguiente:

$$
D I D_{i}=\sum_{j=i} \frac{m_{i j}}{Y i}
$$

Donde $m_{i j}$ es la cantidad de insumos importados procedentes del sector $\mathrm{j}$ empleados por el sector i e $Y_{i}$ la producción efectiva del sector i. Finalmente, el indicador de Deslocalización Internacional Amplio (DIA) mide la intensidad de las adquisiciones intermedias independientemente de su carácter intra o interindustrial. Su expresión para el sector i se puede resumir del siguiente modo:

$$
D I A_{i}=D I R_{i}+D I D_{i}
$$

El indicador restringido, DIR, atiende a la proporción de productos intermedios procedentes del mismo sector que el analizado, intraindustriales, que son importados. El indicador amplio, en cambio mide la cantidad de insumos importados procedentes de sectores distintos al analizado, es decir, de carácter interindustrial. Dentro de la literatura tiende a considerarse el indicador DIR como el que mejor aproxima la medición de los procesos de deslocalización internacional, en la medida que hace referencia a la adquisición de productos intermedios a empresas o filiales procedentes de la misma rama de actividad. Los incrementos en el indicador DID se asocian habitualmente con cambios en la estructura de proveedores, en el sentido de sustituir adquisiciones de producción intermedia doméstica por foránea. Esta interpretación no es, sin embargo, rígida, en la medida que el código de actividad asignado a una determinada actividad segmentada como resultado de una estrategia de fragmentación internacional de la producción puede diferir del principal de la empresa que la implementa.

Se ha optado por presentar una versión de los indicadores que mide la evolución de los insumos importados en relación a la producción sectorial total $\left(Y_{i}\right)$. En este

\footnotetext{
${ }^{5}$ A lo largo del trabajo utilizamos la clasificación europea NACE 1. ISIC Rev. 3 y NACE 1 son equivalentes para un nivel de desagregación de dos dígitos. Cuando se ha empleado un nivel de desglose mayor, se han realizado las conversiones correspondientes.

${ }^{6}$ Para la deflación de los valores interiores correspondientes a la rama NACE 30 se ha empleado el correspondiente índice de precios industriales proporcionado por el INE, ante la amplia variabilidad presentada por el deflactor proporcionado por EU KLEMS.
} 
Gutiérrez, David. Deslocalizaciones internacionales: impacto sobre la estructura manufacturera española (1995-2005).

sentido, existen propuestas alternativas que sitúan en el denominador el total de adquisiciones intermedias o el valor añadido generado por el sector. Como indican Gómez et al. (2006) la versión escogida supone una medición más ajustada de la cuantía en la que se están dejando de producir ciertos insumos internamente ${ }^{7}$.

Los indicadores presentados constituyen una de las aproximaciones cuantitativas más precisas a la hora de capturar la intensidad de los procesos de deslocalización internacional, pero no están exentos de limitaciones. En este sentido, existen al menos dos tipos de reubicaciones que no se reflejarían en los datos presentados: (i) aquellas que implican la reimportación del producto como bien final, no reflejándose en las estadísticas de comercio de productos intermedios y (ii) aquellas que no implican reimportación de ningún tipo, versión que podría suponer incluso una reducción en las adquisiciones de insumos ${ }^{8}$.

El estudio de los indicadores de deslocalización internacional se aborda en dos fases. Se atiende en primer lugar a su evolución en el ámbito manufacturero español, aplicándose las taxonomías propuestas ${ }^{9}$ e identificándose algunas de las principales tendencias registradas. A continuación se ofrece una sistematización de los resultados a través de una propuesta de tipología derivada del comportamiento sectorial respecto a dos variables: (i) la evolución del VAB y (ii) la evolución del indicador de DIR.

\subsubsection{Análisis de indicadores}

La implementación de estrategias deslocalizadoras no constituye una novedad en el sector manufacturero español. Minondo y Rubert (2001), utilizando un enfoque centrado en productos, muestran que este tipo de procesos ya se desarrollaron con intensidad en el periodo 1980-1994, especialmente en los ámbitos productivos más tradicionales y en lo relativo a los intercambios de naturaleza interindustrial. Los datos presentados en el Cuadro 6 reflejan una profundización en esta tendencia tanto para las actividades industriales como para el conjunto de la economía, con especial dinamismo durante el lapso 1995-2000. Los valores del índice amplio muestran, además, que las actividades manufactureras recurren con mayor intensidad a la fragmentación internacional de la producción aunque, como indica la evolución de las tasas de variación medias anuales para el conjunto de la economía, el proceso se ha extendido hacia otros sectores económicos.

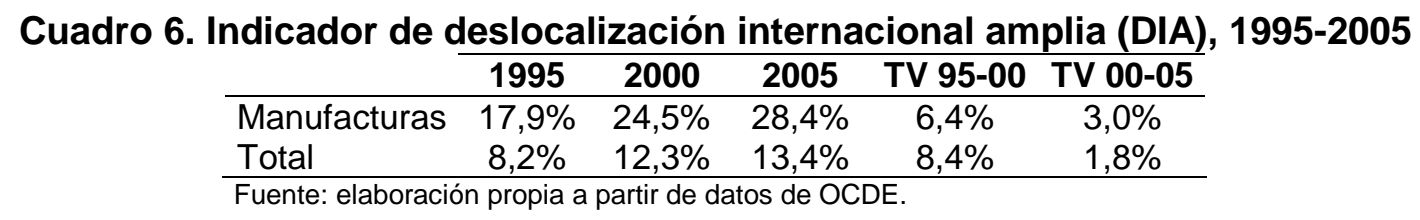

\footnotetext{
${ }^{7}$ En este sentido, las versiones que optan por medir la evolución de las importaciones intermedias respecto al total de inputs pueden recoger disminuciones en la magnitud del indicador cuando las adquisiciones domésticas se incrementan más rápidamente, aunque la importancia relativa de las importadas respecto a la producción total también aumente.

${ }^{8}$ Sería el caso, por ejemplo, de las deslocalizaciones que se han definido introductoriamente como totales, que implican el cese de actividad de una determinada empresa en el ámbito doméstico.

${ }^{9}$ Las tablas input-output proporcionan datos únicamente con un nivel de desagregación de dos dígitos. Para la estimación de los indicadores de DI en las ramas con códigos NACE de tres dígitos se han utilizado los datos sobre adquisiciones intermedias proporcionados por las Structural Business Statistics de Eurostat. Los indicadores de carácter agregado son promedios ponderados.
} 
Cuadro 7. Indicadores DIR, DID y DIA según intensidad tecnológica, 1995-2005

\begin{tabular}{|c|c|c|c|c|c|c|c|c|c|c|}
\hline \multirow[b]{2}{*}{ Código } & \multirow[b]{2}{*}{ Sector } & \multicolumn{4}{|c|}{ DIR } & \multicolumn{4}{|c|}{ DID } & \multirow{2}{*}{$\begin{array}{c}\text { DIA } \\
2005\end{array}$} \\
\hline & & 1995 & 2000 & 2005 & TV 95-05 & 1995 & 2000 & 2005 & TV 95-05 & \\
\hline & Alta tecnología & $12,43 \%$ & $22,51 \%$ & $28,53 \%$ & $8,67 \%$ & $9,34 \%$ & $13,53 \%$ & $19,60 \%$ & $7,69 \%$ & $48,13 \%$ \\
\hline 244 & Fabricación de productos farmacéuticos & $13,30 \%$ & $24,91 \%$ & $33,89 \%$ & $9,80 \%$ & $5,77 \%$ & $10,00 \%$ & $11,84 \%$ & $7,46 \%$ & $45,73 \%$ \\
\hline 30 & Fabricación de maquinaria de oficina, contabilidad e informática & $15,49 \%$ & $32,90 \%$ & $46,76 \%$ & $11,68 \%$ & $11,45 \%$ & $13,08 \%$ & $12,24 \%$ & $0,67 \%$ & $59,00 \%$ \\
\hline 32 & $\begin{array}{l}\text { Fabricación de equipo y aparatos de radio, televisión y } \\
\text { comunicaciones }\end{array}$ & $15,66 \%$ & $28,47 \%$ & $41,25 \%$ & $10,17 \%$ & $8,97 \%$ & $10,46 \%$ & $16,08 \%$ & $6,01 \%$ & $57,33 \%$ \\
\hline 33 & Fabricación de instrumentos médicos, ópticos y de precisión & $2,34 \%$ & $3,92 \%$ & $4,88 \%$ & $7,63 \%$ & $18,94 \%$ & $26,95 \%$ & $47,30 \%$ & $9,58 \%$ & $52,18 \%$ \\
\hline \multirow[t]{2}{*}{353} & Fabricación de aeronaves y naves espaciales & $4,06 \%$ & $7,55 \%$ & $10,22 \%$ & $9,67 \%$ & $12,70 \%$ & $15,51 \%$ & $20,64 \%$ & $4,98 \%$ & $30,86 \%$ \\
\hline & Media-alta tecnología & $15,24 \%$ & $21,67 \%$ & $21,70 \%$ & $3,60 \%$ & $9,54 \%$ & $12,83 \%$ & $15,89 \%$ & $5,24 \%$ & $37,59 \%$ \\
\hline $24 x$ & Productos químicos, excluyendo framacéuticos & $14,62 \%$ & $25,06 \%$ & $32,50 \%$ & $8,31 \%$ & $6,34 \%$ & $10,06 \%$ & $11,36 \%$ & $6,00 \%$ & $43,86 \%$ \\
\hline 29 & Fabricación de maquinaria y equipo n.c.p. & $3,24 \%$ & $6,42 \%$ & $6,31 \%$ & $6,89 \%$ & $11,29 \%$ & $12,86 \%$ & $13,72 \%$ & $1,97 \%$ & $20,03 \%$ \\
\hline 31 & Fabricación de maquinaria y aparatos eléctricos n.c.p. & $7,23 \%$ & $7,60 \%$ & $9,24 \%$ & $2,48 \%$ & $9,18 \%$ & $12,25 \%$ & $22,03 \%$ & $9,15 \%$ & $31,27 \%$ \\
\hline 34 & Fabricación de vehículos automotores, remolques y semirremolques & $23,54 \%$ & $30,98 \%$ & $28,09 \%$ & $1,78 \%$ & $10,48 \%$ & $14,02 \%$ & $16,77 \%$ & $4,81 \%$ & $44,86 \%$ \\
\hline \multirow[t]{2}{*}{$35 x$} & Otro equipo de transporte & $6,09 \%$ & $11,18 \%$ & $13,16 \%$ & $8,01 \%$ & $19,05 \%$ & $22,97 \%$ & $26,59 \%$ & $3,39 \%$ & $39,75 \%$ \\
\hline & Media-baja tecnología & $2,94 \%$ & $3,62 \%$ & $4,79 \%$ & $5,00 \%$ & $16,39 \%$ & $28,32 \%$ & $29,56 \%$ & $6,07 \%$ & $34,35 \%$ \\
\hline 23 & Fabricación de coque, productos de la refinación del petróleo & $1,59 \%$ & $3,80 \%$ & $5,15 \%$ & $12,44 \%$ & $52,61 \%$ & $86,84 \%$ & $87,03 \%$ & $5,16 \%$ & $92,18 \%$ \\
\hline 25 & Fabricación de productos de caucho y plástico & $2,40 \%$ & $4,14 \%$ & $9,67 \%$ & $14,95 \%$ & $24,40 \%$ & $21,87 \%$ & $20,79 \%$ & $-1,59 \%$ & $30,46 \%$ \\
\hline 26 & Fabricación de otros productos minerales no metálicos & $0,14 \%$ & $0,27 \%$ & $1,88 \%$ & $30,11 \%$ & $3,89 \%$ & $5,34 \%$ & $8,14 \%$ & $7,65 \%$ & $10,02 \%$ \\
\hline 27 & Fabricación de metales comunes & $8,21 \%$ & $8,92 \%$ & $5,43 \%$ & $-4,05 \%$ & $8,43 \%$ & $11,16 \%$ & $11,74 \%$ & $3,38 \%$ & $17,17 \%$ \\
\hline 28 & $\begin{array}{l}\text { Fabricación de productos elaborados de metal, excepto maquinaria } \\
\text { y equipo }\end{array}$ & $1,31 \%$ & $1,67 \%$ & $3,42 \%$ & $10,10 \%$ & $12,03 \%$ & $15,93 \%$ & $22,99 \%$ & $6,70 \%$ & $26,41 \%$ \\
\hline \multirow[t]{2}{*}{351} & Construcción y reparación de buques y otras embarcaciones & $5,20 \%$ & $8,74 \%$ & $10,12 \%$ & $6,90 \%$ & $16,25 \%$ & $17,96 \%$ & $20,45 \%$ & $2,33 \%$ & $30,57 \%$ \\
\hline & Baja tecnología & $5,42 \%$ & $7,72 \%$ & $6,92 \%$ & $2,46 \%$ & $6,58 \%$ & $9,28 \%$ & $10,66 \%$ & $4,95 \%$ & $17,58 \%$ \\
\hline $15-16$ & Elaboración de productos alimenticios, bebidas y tabaco & $2,40 \%$ & $3,96 \%$ & $3,85 \%$ & $4,82 \%$ & $6,96 \%$ & $10,63 \%$ & $12,03 \%$ & $5,63 \%$ & $15,88 \%$ \\
\hline $17-19$ & Fabricación de productos textiles, cuero y calzado & $7,99 \%$ & $12,49 \%$ & $12,07 \%$ & $4,21 \%$ & $7,61 \%$ & $8,34 \%$ & $10,18 \%$ & $2,95 \%$ & $22,25 \%$ \\
\hline 20 & $\begin{array}{l}\text { Producción de madera y fabricación de productos de madera y } \\
\text { corcho }\end{array}$ & $8,58 \%$ & $13,49 \%$ & $17,56 \%$ & $7,43 \%$ & $5,71 \%$ & $8,51 \%$ & $8,68 \%$ & $4,28 \%$ & $26,24 \%$ \\
\hline $21-22$ & $\begin{array}{l}\text { Fabricación de papel y de productos de papel y actividades de } \\
\text { edición }\end{array}$ & $12,47 \%$ & $13,66 \%$ & $10,18 \%$ & $-2,00 \%$ & $3,04 \%$ & $5,35 \%$ & $6,95 \%$ & $8,63 \%$ & $17,13 \%$ \\
\hline $36+37$ & $\begin{array}{l}\text { Fabricación de muebles; industrias manufactureras n.c.p. y } \\
\text { reciclado }\end{array}$ & $1,29 \%$ & $2,07 \%$ & $3,40 \%$ & $10,18 \%$ & $10,68 \%$ & $12,70 \%$ & $12,36 \%$ & $1,47 \%$ & $15,76 \%$ \\
\hline
\end{tabular}

Fuente: elaboración propia a partir de datos de OCDE. 
Gutiérrez, David. Deslocalizaciones internacionales: impacto sobre la estructura manufacturera española (1995-2005).

Sin embargo, estas cifras agregadas esconden una amplia diversidad de trayectorias sectoriales. La implementación de estrategias de deslocalización internacional depende de forma decisiva de las características particulares de los sectores involucrados, de las características de la economía nacional objeto de análisis y de factores externos asociados con la competencia planteada por otras áreas geográficas. En el Cuadro 7 se presentan los indicadores DIR, DID y DIA para el sector manufacturero español durante el periodo 1995-2005, desglosados según intensidad tecnológica sectorial.

Una primera apreciación que se deriva del análisis de los indicadores propuestos es la existencia de una correlación positiva en el caso español entre densidad tecnológica e intensidad con la que se recurre a las adquisiciones de insumos en el exterior. En 2005, el indicador DIA registraba las mayores magnitudes para los sectores de alta tecnología (48,1\%), significativamente por encima de los sectores de media-alta y media-baja tecnología (37,6\% y 34,4\%, respectivamente).

En lo relativo a la evolución del indicador restringido, DIR, el que permite una mejor aproximación a la intensidad con la que se están implementando procesos de DI, esta correlación es aún más acusada. Las actividades que acuden en mayor medida a la adquisición de productos intermedios de carácter intraindustrial son las de intensidad alta y media-alta $(28,5 \%$ y $21,7 \%$, respectivamente) muy por encima de las agrupadas bajo los agregados media-baja y baja (5\% y 2,5\%). Un patrón similar se encuentra en los datos presentados para un grupo de siete países europeos por Falk y Wolfmayr (2005) y para España por Gómez et al. (2006). En términos de trayectoria, las actividades de alta tecnología fueron las que incrementaron con mayor intensidad sus adquisiciones de insumos intraindustriales en el exterior, con un crecimiento del DIR por encima del $8 \%$ anual medio, ritmo netamente superior al registrado en el resto de agregados tecnológicos.

El desglose sectorial permite profundizar en las dinámicas que explican la evolución descrita para los indicadores agregados. Todos los sectores de elevada densidad tecnológica experimentan incrementos acelerados en el índice DIR. Sin embargo dos ramas destacan tanto por la intensidad con la que crecen las adquisiciones de insumos intraindustriales como por el nivel que alcanza el indicador: "fabricación de maquinas de oficina, contabilidad e informática" y "fabricación de equipo y aparatos de radio, televisión y comunicaciones"; dos de los sectores que peor trayectoria registran desde el punto de vista de las variables macro (véase Cuadro 4).

Dentro de los sectores con intensidad tecnológica media-alta, los mayores valores del índice DIR se registran en los sectores "productos químicos, excluyendo farmacéuticos" y "fabricación de vehículos automotores, remolques y semirremolques". En términos dinámicos, la industria química incrementa su dependencia respecto a la importación de productos intermedios de su misma rama de forma más intensa. El sector automovilístico sufre los menores incrementos en su indicador DIR dentro de las ramas de alta y media/alta tecnología.

Las actividades de media-baja y baja tecnología presentan valores notablemente inferiores en los indicadores restringidos. Varias ramas incrementan su DIR de forma acelerada, pero partiendo de niveles bajos. Es el caso de los sectores "Fabricación de productos de caucho y plástico", "Fabricación de coque, productos de la 
Gutiérrez, David. Deslocalizaciones internacionales: impacto sobre la estructura manufacturera española (1995-2005).

refinación del petróleo y combustible nuclear" y "Fabricación de productos elaborados de metal, excepto maquinaria y equipo".

Los valores en el indicador diferencia, DID, muestran un menor grado de heterogeneidad entre sectores, alcanzando mayores niveles en las actividades de media-baja tecnología. Su evolución en ciertos sectores, sin embargo, parece estar fuertemente asociada a procesos de creciente internacionalización de la estructura de inputs y no de forma directa a la implementación de procesos de deslocalización en sentido estricto. De este modo, algunos de los ámbitos sectoriales que presentan mayores magnitudes parecen ser altamente dependientes de cierto tipo de importaciones (Gómez et al., 2006): "Fabricación de instrumentos médicos, ópticos y de precisión" respecto a las procedentes del sector "Fabricación de equipo y aparatos de radio, televisión y comunicaciones" (31,9\% de la producción), "Fabricación de productos de caucho y plástico" respecto a "Productos químicos" (13,2\% de la producción) o "Fabricación de coque, productos de la refinación del petróleo" respecto a la importación de productos de origen mineral $(85,8 \%$ de la producción total). En otros casos resulta complejo determinar en qué medida la tendencia puede responder a cambios en el origen de los productos intermedios o a reubicaciones de la actividad productiva que se plasman en importaciones de carácter interindustrial.

La aplicación de las taxonomías TIC (véase Cuadro 8) permite afianzar algunas de las conclusiones apuntadas en el análisis previo. Las industrias productoras de TIC fueron las que presentaron mayores niveles absolutos en el indicador DIR y las que registraron una evolución más acusada en el mismo. Las ramas que hacen un uso intensivo de las TIC, las más dinámicas en términos de crecimiento de la producción, presentan los niveles más bajos e incluso registran un descenso en su DIR en el periodo 2000-2005. La evolución de la DIR fue, igualmente, más intensa en las ramas con niveles altos y medio altos de cualificación.

Cuadro 8. Indicador DIR según posición respecto a las TIC y niveles de cualificación, 1995-2005

\begin{tabular}{lcccc} 
& \multicolumn{4}{c}{ DIR } \\
\cline { 2 - 5 } \multicolumn{1}{c}{ Sector } & $\mathbf{1 9 9 5}$ & $\mathbf{2 0 0 0}$ & $\mathbf{2 0 0 5}$ & TV 95-05 \\
\hline \multicolumn{1}{c}{ TIC } & & & & \\
TIC Productores & $12,27 \%$ & $22,05 \%$ & $25,61 \%$ & $7,64 \%$ \\
TIC - Usuarios & $6,03 \%$ & $8,04 \%$ & $7,90 \%$ & $2,74 \%$ \\
TIC - No usuarios & $8,08 \%$ & $11,75 \%$ & $11,83 \%$ & $3,89 \%$ \\
$\quad$ Cualificación & & & & \\
Alta & $11,88 \%$ & $18,31 \%$ & $23,15 \%$ & $6,90 \%$ \\
Media-alta & $4,36 \%$ & $7,39 \%$ & $9,37 \%$ & $7,95 \%$ \\
Media-baja & $6,55 \%$ & $7,85 \%$ & $7,78 \%$ & $1,73 \%$ \\
Baja & $7,44 \%$ & $11,06 \%$ & $9,85 \%$ & $2,84 \%$ \\
\hline Fuente: elaboración propia a partir de datos de OCDE.
\end{tabular}


Gutiérrez, David. Deslocalizaciones internacionales: impacto sobre la estructura manufacturera española (1995-2005).

Gráfico 1. Distribución sectorial según intensidad deslocalizadora y dinamismo productivo, 1995-2005

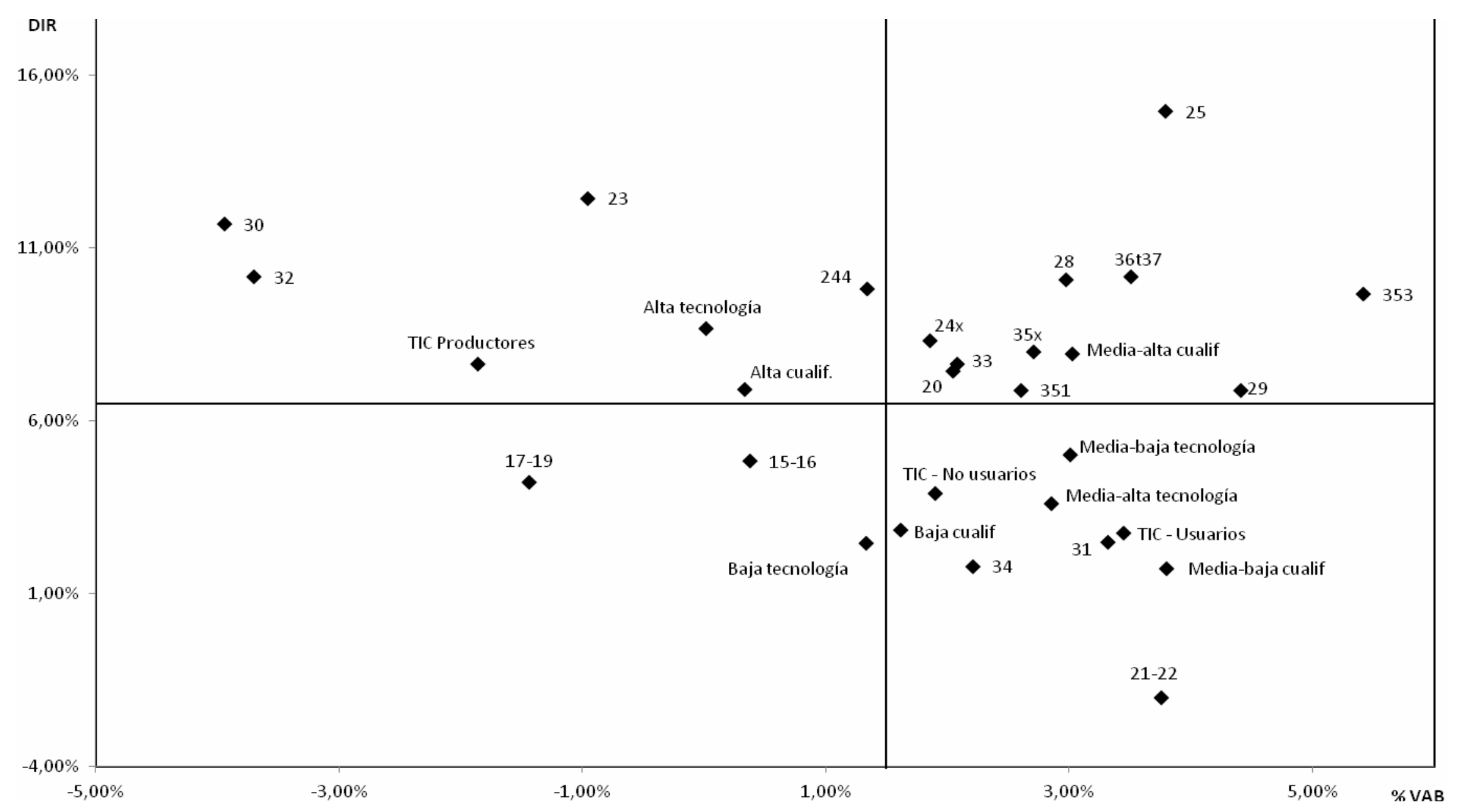

Fuente: elaboración propia a partir de datos de OCDE y EU Klems 
Gutiérrez, David. Deslocalizaciones internacionales: impacto sobre la estructura manufacturera española (1995-2005).

\subsubsection{Síntesis de la evolución de la estructura productiva y los indicadores de deslocalización internacional}

El análisis previo nos ha permitido reunir un conjunto de evidencia acerca de la evolución de la estructura industrial española y la incidencia de los procesos de deslocalización internacional durante el periodo 1995-2005. Tratamos ahora de presentar una visión sistematizada de los procesos en juego y del impacto de las estrategias de fragmentación internacional de la producción en su vertiente deslocalizadora sobre la actividad manufacturera en España. Para ello proponemos la agrupación de los diversos sectores en torno a dos de los indicadores propuestos: (i) la tasa crecimiento anual media del VAB, como expresión de la evolución sectorial y (ii) la tasa de crecimiento del DIR, como aproximación cuantitativa más ajustada de la intensidad que adquieren sectorialmente los procesos de deslocalización internacional.

En el Gráfico 1 se representan los distintos sectores y categorías agregadas según su dinamismo en estos dos ámbitos. Los cuadrantes están delimitados por la tasa de crecimiento media anual no ponderada del VAB (línea vertical) y por la tasa de crecimiento media anual no ponderada del indicador DIR (línea horizontal) durante el periodo 1995-2005 y para las manufacturas españolas. De este modo podemos establecer una tipología orientativa del comportamiento sectorial:

i) Sectores con deslocalización intensa y escaso dinamismo (cuadrante en el margen superior izquierdo): sectores con los códigos NACE 23, 244, 30 y 32, y los agregados "Alta tecnología", "TIC productores" y "Alta cualificación". Se trata de sectores que han experimentado procesos de decrecimiento o estancamiento en términos del volumen de producción y donde existen indicios de estar implementándose procesos de deslocalización internacional.

ii) Sectores con deslocalización intensa y elevado dinamismo (cuadrante en el margen superior derecho): sectores con los códigos NACE 20, 24 (excepto farmacéuticas), 28, 29, 33, 35 y agregado "Media alta cualificación". Se trata de sectores donde el indicador DIR crece con intensidad y que han experimentado cierto dinamismo desde el punto de vista de la evolución del producto.

iii) Sectores con deslocalización baja y escaso dinamismo: (cuadrante en el margen inferior izquierdo): sectores con los códigos NACE 15-16, 17-19 y agregado "Baja tecnología". Ámbitos productivos donde los indicadores de deslocalización muestran menor dinamismo y la evolución en términos de producción ha implicado decrecimiento o estancamiento.

iv) Sectores con deslocalización escasa y elevado dinamismo (cuadrante en el margen inferior derecho): sectores con los códigos NACE 21-22, 31, 34 y agregados "Media-alta tecnología", "Media-baja tecnología", "TIC usuarios", "TIC no usuarios", "Media-baja cualificación" y "Baja cualificación". Sectores en los que el DIR ha evolucionado con menor intensidad y la generación de valor añadido sectorial se ha incrementado dinámicamente.

La evolución de los agregados, al tratarse de indicadores medios ponderados, está influenciada por el diverso peso relativo de cada una de las ramas que los componen. Así, por ejemplo, el agregado "Media-alta tecnología" entra en el tipo (iv) a pesar de que la mayoría de las ramas que lo integran se sitúan en el tipo (ii). En este caso, el escaso incremento del indicador DIR en sector automovilístico (código 
Gutiérrez, David. Deslocalizaciones internacionales: impacto sobre la estructura manufacturera española (1995-2005).

34) sesga hacia abajo la evolución de la categoría "Media-baja tecnología" en su conjunto.

Debe advertirse que las tipologías presentadas no implican una relación de causalidad, en la medida que la evolución de la estructura productiva y el dinamismo sectorial es función de un conjunto amplio de variables y no únicamente de la implementación de estrategias deslocalizadoras. Sin embargo, muestran la profunda heterogeneidad con la que dentro de los diferentes sectores se están desarrollando los procesos de reubicación internacional de la producción y sugieren la existencia de tipos de impacto diversos sobre la trayectoria de los mismos.

\subsection{Contribución de las empresas multinacionales de capital extranjero a la actividad manufacturera española}

Las empresas multinacionales constituyen actores protagónicos en lo relativo a las transformaciones de la división internacional del trabajo vinculadas a los procesos de deslocalización internacional. La totalidad del fenómeno no puede ser explicada mediante las decisiones adoptadas por éstas -las empresas no internacionalizadas también pueden acudir a este tipo de estrategias mediante la externalización transfronteriza de parte de su proceso productivo- pero existe evidencia que apunta hacia su elevada participación en el mismo (letto-Gillies, 2000).

En el caso de la economía española esta relevancia se ve exacerbada por la amplia penetración de las empresas de capital extranjero en el conjunto de actividades industriales y, especialmente, en las actividades de mayor densidad tecnológica (Molero y Álvarez, 2002). En este sentido, Myro y Fernández-Otheo (2005) presentan evidencia que apunta hacia una rápida disminución en la participación perteneciente a no residentes en el capital social de las actividades manufactureras de mayor intensidad tecnológica, lo que resulta consistente con la evidencia presentada a través de los indicadores de deslocalización internacional.

Resulta de interés, por tanto, analizar la evolución de la contribución de las empresas de capital extranjero a los sectores manufactureros nacionales, como síntoma de potenciales transformaciones de la inserción de España en ciertas actividades concretas. Acudimos para ello a las estadísticas sobre actividad de filiales de grupos multinacionales ${ }^{10}$ que proporciona la OCDE en su base de datos sobre globalización ${ }^{11}$. La disponibilidad de datos está limitada al periodo 1999-2005 y, únicamente, a las mediciones de valor añadido generado y trabajadores empleados. La información recopilada se presenta en el Cuadro 9. Aplicamos las tipificaciones propuestas en el apartado anterior a modo de guía para el análisis.

\footnotetext{
${ }^{10}$ OCDE (2007) considera filiales a aquellas empresas que presenten una estructura de propiedad participada en más de un $50 \%$ por capital extranjero.

${ }^{11}$ Las estadísticas sobre actividad de empresas multinacionales de la OCDE utilizan como fuente la Encuesta Industrial de Empresas del Instituto Nacional de Estadística (INE) mientras que los datos proporcionados por EU Klems empleados para el estudio de la estructura productiva se derivan de la contabilidad nacional. Las diferencias metodológicas pueden inducir divergencias en ciertas magnitudes. Nos centramos, sin embargo, en el análisis de trayectorias.
} 


\section{Cuadro 9. Contribución de las empresas multinacionales de capital extranjero al sector industrial español según intensidad} tecnológica, 1999-2005

\begin{tabular}{|c|c|c|c|c|c|c|c|}
\hline \multirow[b]{3}{*}{ Código } & \multirow[b]{3}{*}{ Sector } & \multicolumn{3}{|c|}{ Empleo } & \multicolumn{3}{|c|}{ VA } \\
\hline & & \multicolumn{2}{|c|}{$\begin{array}{l}\text { Participación } \\
\text { relativa }\end{array}$} & \multirow{2}{*}{$\begin{array}{c}\text { TV media } \\
99-05\end{array}$} & \multicolumn{2}{|c|}{$\begin{array}{l}\text { Participación } \\
\text { relativa }\end{array}$} & \multirow{2}{*}{$\begin{array}{c}\begin{array}{c}\text { TV } \\
\text { media }\end{array} \\
99-05\end{array}$} \\
\hline & & 1999 & 2005 & & 1999 & 2005 & \\
\hline & Alta tecnología & & & & & & \\
\hline 244 & Fabricación de productos farmacéuticos & $56,9 \%$ & $48,7 \%$ & $-1,2 \%$ & $59,7 \%$ & $51,7 \%$ & $-2,1 \%$ \\
\hline 30 & Fabricación de maquinaria de oficina, contabilidad e informática & $79,4 \%$ & $29,9 \%$ & $-26,5 \%$ & $88,7 \%$ & $35,6 \%$ & $-35,1 \%$ \\
\hline 32 & Fabricación de equipo y aparatos de radio, televisión y comunicaciones & $32,7 \%$ & $29,8 \%$ & $-4,3 \%$ & $35,9 \%$ & $31,7 \%$ & $-1,1 \%$ \\
\hline 33 & Fabricación de instrumentos médicos, ópticos y de precisión & $13,9 \%$ & $14,5 \%$ & $4,4 \%$ & $19,9 \%$ & $18,1 \%$ & $-0,1 \%$ \\
\hline \multirow[t]{2}{*}{353} & Fabricación de aeronaves y naves espaciales & n.d & $53,3 \%$ & n.d & n.d & $64,1 \%$ & n.d \\
\hline & Media-alta tecnología & & & & & & \\
\hline $24 x$ & Productos químicos, excluyendo framacéuticos & $37,7 \%$ & $34,3 \%$ & $-0,8 \%$ & $48,2 \%$ & $42,6 \%$ & $-1,9 \%$ \\
\hline 29 & Fabricación de maquinaria y equipo n.c.p. & $16,4 \%$ & $20,0 \%$ & $6,0 \%$ & $21,3 \%$ & $25,9 \%$ & $7,3 \%$ \\
\hline 31 & Fabricación de maquinaria y aparatos eléctricos n.c.p. & $37,5 \%$ & $28,4 \%$ & $-5,5 \%$ & $48,4 \%$ & $34,2 \%$ & $-4,4 \%$ \\
\hline 34 & Fabricación de vehículos automotores, remolques y semirremolques & $59,9 \%$ & $61,6 \%$ & $0,6 \%$ & $64,2 \%$ & $65,5 \%$ & $-0,1 \%$ \\
\hline \multirow[t]{2}{*}{$35 x$} & Otro equipo de transporte & $23,0 \%$ & $21,0 \%$ & $-0,5 \%$ & $40,5 \%$ & $31,4 \%$ & $-1,9 \%$ \\
\hline & Media-baja tecnología & & & & & & \\
\hline 23 & Fabricación de coque, productos de la refinación del petróleo & n.d & n.d & n.d & n.d & n.d & n.d \\
\hline 25 & Fabricación de productos de caucho y plástico & $31,2 \%$ & $30,0 \%$ & $1,5 \%$ & $41,6 \%$ & $39,1 \%$ & $1,8 \%$ \\
\hline 26 & Fabricación de otros productos minerales no metálicos & $9,1 \%$ & $8,1 \%$ & $0,6 \%$ & $17,7 \%$ & $14,4 \%$ & $1,2 \%$ \\
\hline 27 & Fabricación de metales comunes & $15,5 \%$ & $23,1 \%$ & $7,4 \%$ & $23,0 \%$ & $30,8 \%$ & $9,6 \%$ \\
\hline 28 & $\begin{array}{l}\text { Fabricación de productos elaborados de metal, excepto maquinaria y } \\
\text { equipo }\end{array}$ & $3,8 \%$ & $4,4 \%$ & $6,4 \%$ & $6,1 \%$ & $6,5 \%$ & $3,6 \%$ \\
\hline 351 & $\begin{array}{l}\text { Construcción y reparación de buques y otras embarcaciones } \\
\text { Baja tecnología }\end{array}$ & n.d & $2,8 \%$ & n.d & n.d & $3,1 \%$ & n.d \\
\hline $15-16$ & Elaboración de productos alimenticios, bebidas y tabaco & 12,6 & 9,4 & $-4,0 \%$ & 20,3 & 16,2 & $-1,5 \%$ \\
\hline $17-19$ & Fabricación de productos textiles, cuero y calzado & 3,5 & 3 & $-8,6 \%$ & 6,3 & 4,8 & $-9,8 \%$ \\
\hline 20 & Producción de madera y fabricación de productos de madera y corcho & 2 & 1,5 & $-6,9 \%$ & 3,2 & 1,5 & $-12,3 \%$ \\
\hline $21-22$ & Fabricación de papel y de productos de papel y actividades de edición & 8,3 & 10,1 & $6,0 \%$ & 11,4 & 12,9 & $5,6 \%$ \\
\hline $36 \mathrm{t} 37$ & Fabricación de muebles; industrias manufactureras n.c.p. y reciclado & 4,4 & 3,9 & $-1,4 \%$ & 7,2 & 5,4 & $-3,9 \%$ \\
\hline
\end{tabular}


Gutiérrez, David. Deslocalizaciones internacionales: impacto sobre la estructura manufacturera española (1995-2005).

Los sectores de tipo (i) -caracterizados por una elevada intensidad deslocalizadora, un escaso dinamismo y ampliamente penetrados por capitales foráneos- muestran reducciones significativas en la aportación procedente de los grupos multinacionales. Este proceso ha sido de una intensidad excepcional en las actividades dedicadas a la fabricación de equipos informáticos (código 30), en las que tanto el empleo como el valor añadido asociado a la actividad de las filiales han experimentado una abrupta caída. Los sectores "Fabricación de equipo y aparatos de radio, televisión y comunicaciones" (código 32) y "Fabricación de productos farmacéuticos" (código 244) registran también reducciones significativas en las dos variables consideradas.

Dentro de los sectores enmarcados en la tipología (ii), deslocalización intensa y elevado dinamismo, los resultados son heterogéneos. Existen sectores ampliamente penetrados por el capital extranjero donde la aportación de las filiales registra una evolución favorable. Es el caso de las actividades dedicadas a la fabricación de instrumental médico y de precisión (código 33) y, especialmente, las de maquinaria de equipo (código 29). La trayectoria es la opuesta, en cambio, en las ramas "otros equipos de transporte" (código 35) y "productos químicos, excepto productos farmacéuticos" (código 24X). En los sectores restantes la actividad de empresas foráneas es escasamente significativa (códigos 20 y 28 ).

En lo referido a las actividades agrupadas bajo la tipología (iii), deslocalización baja y escaso dinamismo, se observa un comportamiento negativo en los sectores industriales de alimentación (códigos 15-16), donde la participación extranjera es relativamente importante. No lo es tanto en las actividades dedicadas a la fabricación de productos textiles (códigos 17-19), aunque la contribución de las filiales en términos de valor añadido y empleo cae también con rapidez.

Entre las actividades tipo (iv), de baja deslocalización y elevado crecimiento en términos de valor añadido, la aportación de las filiales sigue una trayectoria negativa en la industria automovilística (código 34), fundamentalmente en términos de empleo, y en las actividades dedicadas a la producción de maquinaria y aparatos eléctricos (código 31), tanto en términos de valor añadido como de empleo.

La tendencia general de la actividad asociada a los grupos transnacionales ha sido, por tanto, la de una minoración de su importancia para el conjunto de la industria española y una trayectoria negativa en términos de empleo y niveles productivos, aunque con resultados heterogéneos (crece en todas las ramas de media-baja tecnología). Sin embargo, la evolución ha sido especialmente negativa en los sectores agrupados bajo los tipos (i) y (iii), como muestra el Cuadro 10. En el caso de las actividades tipo (i), intensa deslocalización y escaso dinamismo, el papel de los grupos multinacionales se antoja como clave para explicar la evolución sectorial. Se trata de ámbitos productivos acerca de los cuales existen fuertes indicios de deslocalización (rápido incremento de los insumos intraindustriales importados), altamente penetrados por capital extranjero y donde se registran claras tendencias negativas en el empleo y el valor añadido asociado a las filiales de grupos multinacionales. La dependencia respecto al capital foráneo no es una de tipo coyuntural ni fácilmente superable, sino que está asociada a la configuración particular de los mercados en este tipo de actividades. Prima la competencia oligopólica en sectores de elevada densidad tecnológica donde se opera con 
Gutiérrez, David. Deslocalizaciones internacionales: impacto sobre la estructura manufacturera española (1995-2005).

rendimientos crecientes a escala que favorecen la concentración y existen fuertes barreras de entrada (Martínez González-Tablas, 2007b).

Cuadro 10. Empresas multinacionales de capital extranjero en el sector manufacturero español según tipos, tasas de variación, 1999-2005

\begin{tabular}{ccc} 
& \multicolumn{2}{c}{$1999-2005$} \\
\hline Tipos & TV VAB & $\begin{array}{c}\text { TV } \\
\text { Empleo }\end{array}$ \\
\hline (i) & $-5,55 \%$ & $-4,29 \%$ \\
(ii) & $0,73 \%$ & $1,47 \%$ \\
(iii) & $-3,61 \%$ & $-5,17 \%$ \\
(iv) & $-0,14 \%$ & $-0,02 \%$ \\
\hline Fuente: elaboración propia a partir de \\
datos de OCDE.
\end{tabular}

La fuerte caída de la actividad multinacional en los sectores que hemos calificado de tipo (iii), caracterizados por bajos índices de deslocalización y escaso dinamismo productivo, sugiere dos posibles líneas explicativas complementarias. Se trata de sectores de carácter tradicional, con dificultades para introducir modificaciones en los procesos productivos que deriven en diferenciación de sus productos y, por tanto, intensamente afectados por la competencia planteada desde países con bajos salarios. Este contexto apunta hacia la posibilidad de que los ajustes en estos sectores se estén implementado por dos vías: (i) reestructuraciones que no implican reubicación internacional de la producción y (ii) a través de procesos de deslocalización internacional de carácter total y que no se plasman en un incremento de los flujos comerciales intraindustriales que estamos considerando como indicador. Tal como apuntan Gómez et al. (2006) el indicador DIR tiende a infravalorar la magnitud de los procesos deslocalizadores en los sectores que se ajustan a este patrón.

\section{IMPLICACIONES DEL CASO ESPAÑOL PARA EL ESTUDIO SOBRE DESLOCALIZACIONES INTERNACIONALES}

Los principales resultados obtenidos a partir del trabajo de carácter aplicado permiten apuntar algunas consideraciones de naturaleza más amplia en torno a los enfoques comúnmente aplicados al estudio de los procesos de deslocalización internacional:

i) En la literatura sobre DI suele subrayarse la disparidad entre percepción pública de los procesos, su gran cobertura mediática y el temor suscitado acerca de sus potenciales consecuencias, y la envergadura real que hasta el momento han adquirido los mismos ${ }^{12}$ El caso de España sugiere, sin embargo, que los efectos derivados de los procesos de reubicación pueden ser significativos cuando son considerados a escala sectorial y que estos pueden inducir transformaciones de cierto calado en las estructuras productivas nacionales. Tomado como agregado, la evolución del conjunto de actividades manufactureras es variable de procesos de muy diversa índole, pero la implementación de estrategias de reubicación,

\footnotetext{
${ }^{12}$ Véase, por ejemplo, Auer et al. (2006).
} 
Gutiérrez, David. Deslocalizaciones internacionales: impacto sobre la estructura manufacturera española (1995-2005).

especialmente en economías y ámbitos productivos ampliamente penetrados por empresas multinacionales, reclama ser tenida en cuenta como factor significativo.

ii) Dentro de las líneas teóricas que tratan de explicar los efectos inducidos por las DI, abundan los enfoques de juego de suma positiva o "todos ganan" (Luengo, 2009). Milberg et al. (2007) distinguen entre dos tipos de planteamientos: aquellos que hacen énfasis en las ganancias estáticas, vinculados a las aportaciones realizadas desde la teoría del comercio internacional, y otros que se centran en las ventajas dinámicas que se derivan de la reubicación espacial de la producción.

Los primeros consideran que las posibilidades incrementadas de fragmentación internacional de la cadena productiva surgidas de la mano de innovaciones organizativas y tecnológicas inducen una extensión del principio de ventaja comparativa: las ganancias de eficiencia asociadas a la especialización según la dotación factorial relativa ya no se obtienen únicamente como resultado del comercio internacional de bienes y servicios finales, sino que se amplían al terreno de los consumos intermedios. A través de la deslocalización, las empresas obtienen posibilidades incrementadas de concentrarse en aquellas partes de la cadena productiva en las que acumulan mayores ventajas, incrementado la eficiencia y el bienestar global (Arndt, 1998). Siempre que los perjudicados a consecuencia de la fragmentación internacional de la producción sean compensados, será posible acceder a ganancias paretianas para el conjunto de la economía (Mankiw y Swagel, 2005).

El segundo enfoque se centra en los efectos dinámicos derivados del impacto que sobre la estructura de costes inducen los procesos de DI de la producción. Los efectos beneficiosos se obtendrían a través de dos canales con fuertes vinculaciones: (i) vía reducción de los precios de los productos intermedios y su efecto derivado sobre la demanda y la inversión y/o (ii) vía incremento de los beneficios y su consiguiente reinversión en el ámbito productivo. Un ejemplo de este tipo de posicionamientos es el trabajo de Catherine Mann (2003) acerca de los efectos inducidos sobre el crecimiento como consecuencia del abaratamiento de los productos TIC propiciado, en parte, por las estrategias de DI implementadas por los grupos multinacionales del sector. Así, en EE.UU. esta reducción de costes y precios se habría materializado en aumentos de la inversión que, a su vez, habrían permitido acceder a ganancias adicionales de productividad, contribuyendo por ambas vías al crecimiento económico.

El análisis del caso español sugiere que los enfoques basados en análisis estáticos de eficiencia encuentran problemas si son aplicados de forma mecánica independientemente del contexto geográfico considerado y de la configuración de la estructura productiva que caracterice al mismo. Existen dudas razonables, a la vista de la disminución registrada en la contribución de las empresas multinacionales de capital extranjero y de la evolución sectorial de las actividades tipo (i), de que los recursos liberados por las empresas a través de la implementación de estrategias de fragmentación internacional de la producción se hayan traducido en una reespecialización en fases de la cadena productiva vinculadas con la generación de mayor valor añadido, al menos en el ámbito geográfico español. En un contexto caracterizado por la creciente movilidad de las empresas multinacionales y la transformación de la división internacional del trabajo no parecen existir garantías de 
Gutiérrez, David. Deslocalizaciones internacionales: impacto sobre la estructura manufacturera española (1995-2005).

que la aplicación de los recursos liberados se materialice en la economía desde la que se deslocaliza.

El enfoque dinámico, en cambio, introduce consideraciones de más amplio alcance. En este sentido, la evidencia presentada acerca del impacto de las DI en la estructura productiva española sugiere la existencia de efectos directos negativos sobre la evolución de algunas de las ramas de mayor densidad tecnológica, especialmente las manufacturas productoras de TIC. Existe la posibilidad, sin embargo, de que el impacto vía reducción de precios haya generado tendencias contrarias en otros sectores económicos, especialmente los usuarios intensivos de TIC, operando a través de una inversión acrecentada y la posibilidad de acceder a incrementos adicionales de productividad, y resultando en ganancias netas para el conjunto de la economía española. Sin embargo, éste dista de ser un resultado garantizado. Como indican Milberg y Winkler (2010), no puede asumirse de forma apriorística que los mecanismos sugeridos por el enfoque dinámico sean suficientes para compensar los efectos directos derivados de la reubicación internacional de la producción.

\section{CONCLUSIONES}

La evidencia empírica recopilada muestra la complejidad del estudio de los procesos asociados con las DI, como consecuencia de su intersección con una multiplicidad de planos y de la ausencia de material estadístico específicamente dirigido a la medición del fenómeno. Sin embargo, podemos extraer una serie de conclusiones como resultado del recorrido realizado:

i) La existencia de una amplia diversidad de trayectorias en cuanto a la intensidad con la que se acometen estrategias de deslocalización internacional y el tipo de impacto que inducen en los diversos sectores. Las cuatro tipologías definidas, aunque de carácter orientativo, muestran que los procesos de reubicación no afectan de forma homogénea a todos los ámbitos productivos ni inducen las mismas trayectorias en términos de evolución sectorial.

ii) Se identifican sectores donde existen fuertes indicios acerca de la implementación de procesos deslocalizadores. Aquellos que se han definido como de tipo (i), que experimentan un fuerte incremento de su indicador de DIR en un contexto de evolución negativa de las variables macroeconómicas clave (retrocesos en términos de empleo y generación de valor añadido). Se trata de sectores de elevada densidad tecnológica, eminentemente relacionados con la producción de TIC, que hacen un uso intensivo de trabajo altamente cualificado y ampliamente penetrados por capitales foráneos. La evolución de la actividad de los grupos multinacionales (fuerte caída en términos de generación de valor añadido y empleo) sugiere cambios en las estrategias empresariales respecto a sus patrones de ubicación y una pérdida de relevancia del sector industrial español en estos ámbitos.

iii) Los sectores tradicionales, caracterizados por procesos productivos relativamente estandarizados y un menor dinamismo en términos de evolución de la demanda en los mercados mundiales, parecen estar sujetos a intensos procesos de restructuración en el contexto español, especialmente la industria textil y alimentaria. En este sentido, existen indicios de que los indicadores seleccionados tienden a minusvalorar los procesos de reubicación espacial en 
Gutiérrez, David. Deslocalizaciones internacionales: impacto sobre la estructura manufacturera española (1995-2005).

estos sectores, pero también de que los ajustes pueden estar implementándose a través de otras vías distintas.

iv) En relación a la hipótesis planteada de forma introductoria, la evidencia presentada sugiere que los procesos de DI han jugado un papel relevante en la evolución de la estructura manufacturera española en el periodo 1995-2005. La reversión del proceso de creciente importancia relativa de las actividades de alta tecnología parece estar fuertemente asociado con cambios en las estrategias empresariales de ubicación en estos sectores, especialmente en lo relativo al posicionamiento de los grupos multinacionales de capital extranjero.

v) El trabajo presentado sugiere la necesidad de continuar profundizando en el estudio de las causas y consecuencias de los procesos de DI, evitando la utilización de enfoques de corte apriorístico del tipo "todos ganan". 
Gutiérrez, David. Deslocalizaciones internacionales: impacto sobre la estructura manufacturera española (1995-2005).

\section{BIBLIOGRAFÍA}

Álvarez, I. y Molero, J. (2002): "Las empresas multinacionales y la innovación tecnológica: dinámica internacional y perspectiva española", Información Comercial Española, № 818, 101-123.

Álvarez, M.E., Vega, J., Myro, R. (2007): "Cambios recientes en la especialización inter-industrial de las manufacturas españolas", Papeles de Economía Española, ํㅜ 112, 2-21.

Arndt, S.W. (1998): "Super-specialization and the gains from trade", Contemporary Economic Policy, vol. XVI, 480-485.

Bottini, N., Ernst, C., y Luebker, M. (2007): "Offshoring and the labour market: What are the issues?", Economic and labour market paper, Organización Internacional del Trabajo, 2007/11.

Cadarso, M.A., López, L.A. y Tobarra, M.A. (2007): "Especialización vertical, outsourcing e inversión directa en la industria española", Revista de Economía Mundial, no 16, 27-55.

EU Klems (2008): EU KLEMS Database, marzo de 2008, véase Timmer, M., O'Mahony M y van Ark, B., The EU KLEMS Growth and Productivity Accounts: An Overview, University of Groningen \& University of Birmingham; descargable en www.euklems.net.

Falk, M. y Wolfmayr, Y. (2005): "Employment Effects of Outsourcing to Low Wage Countries Empirical Evidence for EU Countries", WIFO Working Papers, The Austrian Institute for Economic Research, № 262.

Feenstra, RC. y Hanson, GH. (1999): "The Impact of Outsourcing and HighTechnology Capital on Wages: Estimates for the United States, 1979-1990", The Quarterly Journal of Economics, vol. 114, ํo 3, 907-940.

Freeman, R.B. (2007): "The challenge of the growing globalization of labor markets to economic and social policy" en Paus, E. (ed.), Global capitalism unbound: winners and losers from offshore outsourcing, Palgrave Macmillan, Nueva York.

Gómez, N., López, L.A. y Tobarra, M.A. (2006): "Pautas de deslocalización de la industria española en el entorno europeo (1995-2000). La competencia de los países de bajos salarios", Boletín Económico del ICE, ํo 2884, 25-41.

Gordo, E. (2007): "La competitividad internacional de la industria", Papeles de Economía Española, № 112, 156-169.

Hausmann, R., Hwang, J. y Rodrik, D. (2007): "What you exports matters", Journal of Economic Growth, vol. 12, no 1, 1-25.

Hausmann, R. y Klinger, B. (2006): "Structural Transformation and Patterns of Comparative Advantage in the Product Space", KSG Faculty Research Working Paper Series, John F. Kennedy School of Government, RWP06-041.

Huberty (2010): "The Dissolution of Sectors: Do Politics and Sectors Still Go Together?", BRIE Working Paper, Berkeley Roundtable on the International Economy, no 189.

letto-Gillies, G. (2000): "Globalisation: an analysis of theoretical perspectives and dominant causes", Research Papers in International Business, ํㅡ 24-00.

Lall, S. (2003): "Reinventing industrial strategy: The role of government policy in building industrial competitiveness", QEH Working Paper Series, ㄲo 111.

Luengo, F. (2009): "Las deslocalizaciones internacionales. Una visión desde la economía critica", ICEI Working Papers, WP10/09. 
Gutiérrez, David. Deslocalizaciones internacionales: impacto sobre la estructura manufacturera española (1995-2005).

Luengo, F. y Álvarez, I. (2009): "Impact of international offshoring on the labour market. A reflection on the conceptual and methodological aspects", Papeles de Europa, no 18, 50-67.

Mankiw, N.G. y Swagel, P. (2005): "The Politics and Economics of Offshore Outsourcing", Journal of Monetary Economics, vol. 53, ํㅜ 5, 1027-1056.

Mann, C. (2003): "Globalization of IT Services and White Collar Jobs: The Next Wave of Productivity Growth", International Economics Policy Briefs, Institute for International Economics, PB03-11.

Martínez González-Tablas, A. (2007): Economía política mundial. II. Pugna e incertidumbre en la economía mundial, Ariel, Barcelona.

- (2007b): Economía política mundial. I. Las fuerzas estructurantes, Ariel, Barcelona.

Minondo, A. y Rubert, G. (2001): "La evolución del outsourcing en el sector manufacturero", Boletín Económico de ICE, nำ2709, 11-19.

Milberg, W. (2004): "Cambio del comercio ligado a los sistemas mundiales de producción. ¿Qué política seguir?”, Revista Internacional del Trabajo, vol. 123 no 1-2, 49-101.

Milberg, W., Mahoney, N., Schneider, M y von Armin, R. (2007): "Dynamic gains from US services offshoring: A critical view" en Paus, E. (ed.), Global Capitalism Unbound, Palgrave Macmillan, Nueva York.

Milberg, W. y Winkler, D. (2010): "Financialisation and the dynamics of offshoring in the USA", Cambridge Journal of Economics, vol. 34, no 2, 275-293.

Molero, J. (2009): "El futuro de la industria española: un análisis desde la perspectiva de la innovación tecnológica" en Velarde, J. (coord.), El futuro de la economía española, Colección Mediterráneo Económico, nº 16, 155-170.

Myro, R. y Fernández-Otheo, C.M. (2005): "La deslocalización de empresas en España. La atracción de la Europa Central y del Este", Papeles del Este: Transiciones poscomunistas, vol. 10, 1-20.

Nayyar, D. (2006): "Globalisation, history and development: a tale of two centuries", Cambridge Journal of Economics, vol. 30, no 1, 137-159.

Observatorio Industrial del Sector Construcción (2009): Interrelaciones productivas del sector de la construcción y la industria de materiales. Identificación de perfiles profesionales y formación asociada, Ministerio de Industria, Turismo y Comercio.

OCDE (2005): OECD Handbook on Economic Globalisation Indicators, Organización para la Cooperación y el Desarrollo Económico, París.

Robinson, C., Stokes, L., Stuivenwold, E. y Van Ark, B. (2003): "Industry Structure and Taxonomies" en O'Mahony y Van Ark (eds.), EU productivity and competitiveness: An industry perspective. Can Europe resume the catching-up process?, Comisión Europea.

Rodrik, D. (2006): "Industrial Development: Stylized Facts and Policies", Mimeo, Kennedy School of Government.

Velasco, R. y Plaza, B. (2003): "La industria española en democracia, 1978-2003", Economía Industrial, no 349-350, 155-180. 